\title{
Unit Commitment under the Environment of Wind Power and Large-Scale Bilateral Transactions
}

\author{
Fang Liu1, Yi Pan1', Junfeng Yang², Zhiqiang Luo², Lihua Liu² \\ ${ }^{1}$ China Electric Power Research Institute, Haidian District, Beijing, China \\ ${ }^{2}$ State Grid Corporation of China, Xicheng District, Beijing, China \\ Email:1197579563@qq.com
}

How to cite this paper: Liu, F., Pan, Y., Yang, J.F., Luo, Z.Q. and Liu, L.H. (2017) Unit Commitment under the Environment of Wind Power and Large-Scale Bilateral Transactions. Energy and Power Engineering, 9, 611-624.

https://doi.org/10.4236/epe.2017.94B067

Received: February 6, 2017

Accepted: March 30, 2017

Published: April 6, 2017

\begin{abstract}
Bilateral electric power contract is settled based on contract output curve. This paper considered the bilateral transactions execution, new energy accommodation, power grid security and generation economy, considering the executive priority of different power components to establish a multi-objective coordination unit commitment model. Through an example to verify the effectiveness of the model in promoting wind power consumption, guaranteeing trade execution, and improving power generation efficiency, and analyzed the interactions to each other among the factors of wind power, trading and blocking. According to the results, when wind power causes reverse power flow in the congestion line, it will promote the implementation of contracts, the influence of wind power accommodation to trade execution should be analyzed combined with the grid block, the results can provide reference for wind power planning.
\end{abstract}

\section{Keywords}

Bilateral Electric Power Contract, Unit Commitment, Wind Power Accommodation, Transaction Execution, Congestion

\section{Introduction}

Differs from foreign typical electric power market, electricity market in our country is still in the phase of transition from traditional scheduling to fully market. It is neither an American PJM full power centralized price bidding, nor the British market both generator and users to submit the output curve, due to both market power and planned power, and the lack of full power offer or increase or decrease offer for power balance, bilateral deals abroad to participate in 
the power balance method is not suitable for the current stage in our country.

Related researches have been carried out in our country as follows. Literature [1] analyzed the bilateral trade mode under wholesale competition market, according to the market target to propose the bilateral trade model, and the corresponding settlement algorithm is analyzed according to the different model. Literatures [2] [3] [4] [5] introduced the experience of foreign typical bilateral trade market mode from aspects of the bilateral transaction subjects, types, means of exchange and so on, a method is. Literatures [6] [7] [8] [9] [10] introduced the bilateral trade pricing, game model and trading strategy optimization problems. Literature [11] analyzed the bilateral trade trading mode, offer model and the model of deal-making, by using the model trading scheme simulation calculation is studied. The literature [12] introduced the bilateral trade practice carried out in the south power market. Overall, the study of the bilateral trade is more focused on the operation of the bilateral trade mode, it is lack of the study on bilateral electricity contract to participate in power balance.

This article put forward a unit commitment model, which would achieve the coordination of a variety of objectives, promoting wind power consumption, ensuring contracts execution, achieving different power components coordination, guaranteeing fairness among power plants.

\section{Multi-Objective Coordinated Optimization Modeling Method}

The unit commitment model needs to meet general requirements as follows: first, consider uncertainty of wind power and grid security to promote the accommodation of wind power; second, take transaction execution, generation economy and security into consideration, find the unit commitment that costs least meanwhile transaction executes the most and wind power consumption is ensured.

Using the confidence interval method to model the uncertainty of wind power uncertainty [13] [14], according to the wind power prediction and error distribution model to obtain wind power fluctuations confidence interval, take the upper and lower limits of interval as wind power extreme scenarios. The cost of wind power is not considered into the power generation cost, according to the wind power purchase policy, this article will give priority to ensure that wind power consumption, to achieve the above goal, wind power uncertainty model will be treated as constraints, given a confidence interval, wind power generation output within the interval can be consumed totally.

Establish bilateral electric power contract and Sangong contract respectively, thus the optimization results can directly reflect the implementation of different power components, obtaining bilateral perform curve and Sangong completion. According to the implementation priority of the contract, set the weight of the different components of power, to minimize the total contract reduction. At the same time, establish related constraints on bilateral electric power contract and Sangong contract, to ensure that all types of contract reduction taking into ac- 
count of the fair implementation among power plants.

Contract completion rate related to power plants interests, through contract reduction factor to achieve the fair distribution of contract reductions among the power plants. When the bilateral transaction is an electric quantity contract, there is only one contract cutting factor for both bilateral and Sangong power, while the bilateral power contract is electric power contract, the bilateral and Sangong power will respectively use different cutting factors. The bilateral electric power contract cutting factor is shown in (1), Sangong contract cutting factor is shown in (2).

$$
\begin{gathered}
S X_{i}=\frac{H S_{i}}{\sum_{i} H S_{i}} \\
J X_{i}=\frac{H J_{i}}{\sum_{i} H J_{i}}
\end{gathered}
$$

In Equation (1), $S X_{i}$ is the bilateral electric power contract cutting factor for plant $\mathrm{i} ; H S_{i}$ is the total amount of bilateral power for plant $\mathrm{i} ; J X_{i}$ is the Sangong contract cutting factor for plant $i{ }_{H} S_{i}$ is the total amount of Sangong power for plant $\mathrm{i}$.

Power generation enterprises want to maximize the transaction execution at the lowest cost, through the establishment of power generation economy goal, the optimization process will automatically find the optimal allocation of units, the better economy the unit will be given priority to power generation to complete its power plant contract, to ensure that the power plant complete the contract requirements at the lowest cost.

\section{Objective Function}

In order to balance the implementation of the contract and power generation economy, this paper used joint optimization of the contract adjustment and power generation cost, the priority of the two types of targets is coordinated by introducing the penalty factor $M_{1}$ and $M_{2}$, the objective function is shown as Equation (3)

$$
\min \left(W_{1} \bullet \Delta S+W_{2} \bullet \Delta J\right) \cdot M_{1}+C(P) \cdot M_{2}
$$

In Equation (3), part of symbols expression is as follows:

$$
\begin{gathered}
\Delta S=\sum_{g=1}^{H} \sum_{t=1}^{T} P_{g, t, 0}-\sum_{i=1}^{N} \sum_{t=1}^{T} P_{i, S, t} \\
\Delta J=\sum_{g=1}^{H} J_{g, 0}-\sum_{i=1}^{N} \sum_{t=1}^{T} P_{i, J, t} \\
C(P)=\sum_{i=1}^{N} \sum_{t=1}^{T}\left(f_{i, t}+S_{U i, t}+S_{D i, t}\right)
\end{gathered}
$$

Equation (4) is the amount of bilateral transaction cutting, Equation (5) is the amount of Sangong contract cutting, Equation (6) is generation cost, including operation cost, start-up cost and downtime cost. 
In the above equations, all the variables in the objective function are the values under the wind power prediction scenario. $\mathrm{H}$ is number of thermal plant; $\mathrm{N}$ is number of thermal unit; $\mathrm{T}$ is number of time intervals; $W_{1}$ is the execution weight of bilateral electric contract; $W_{2}$ is the execution weight of Sangong contract; $M_{1}$ is the penalty factor of contract reduction; $M_{2}$ is the penalty factor of generation cost; $\Delta S$ is the total amount of bilateral transaction reductions (MWh); $\Delta J$ is the total amount of Sangong contract reductions (MWh); $P_{g, t, 0}$ is the bilateral transaction output for plant g at time t(MW); $J_{g, 0}$ is the quantity of Sangong contract for plant g $(\mathrm{MWh}) ; P_{i, S, t}, P_{i, J, t}$ is the actual output corresponding to bilateral transaction and Sangong contract respectively for unit $\mathrm{i}$ at time $\mathrm{t}(\mathrm{MW}) ; f_{i, t}$ is the operation cost for unit $\mathrm{i}$ at time $\mathrm{t} ; S_{U i, t}, \quad D i, t$ is the start-up cost and downtime cost respectively.

$M_{1}$ and $M_{2}$ are decided in accordance with the priority of transaction execution and power generation economy, when the contract execution is given priority, the order of magnitude of $M_{1}$ is much higher than $M_{2}$, otherwise, $M_{2}$ is much higher than $M_{1} . W_{1}$ and $W_{2}$ will be decided in accordance with the priority of different power components, when the bilateral power is given priority, $W_{1}$ will take a larger value, otherwise, $W_{2}$ will take a larger value, specific options need to be combined with relevant national policies and rules.

\section{Constraints}

According to "the worst feasible and the expect optimal" optimization principle, constraints consist of two parts: constraints under wind power prediction scenario and constraints under wind power extreme scenarios. The wind power prediction scenario is the desired operating condition, it is going to ensure the realization of wind power consumption, transaction execution, system operation safety and power generation economy under the desired operating conditions. The constraints under wind power extreme scenarios improve the reliability of unit commitment.

\subsection{Constraints under Predicted Wind Power Scenario}

Constraints under predicted wind power scenario including power balance, unit operation limits, constraints related to bilateral transactions and Sangong contracts, power flow and reserve requirements, etc., as follows:

$$
\begin{gathered}
\sum_{i=1}^{N} P_{i, t}+\sum_{j=1}^{W} P_{w j, t}=L_{t} \\
\Delta S_{g}=\sum_{t=1}^{T} P_{g, t, 0}-\sum_{i \in N_{g}} \sum_{t=1}^{T} P_{i, S, t}, \quad g=1,2, \cdots, H \\
\Delta S_{g}=S X_{g} \cdot \Delta S \\
P_{g, t, 0}-\sum_{i \in N_{g}} P_{i, S, t} \geq 0 \\
\Delta J_{g}=J_{g, 0}-\sum_{i \in N_{g}} \sum_{t=1}^{T} P_{i, J, t}
\end{gathered}
$$




$$
\begin{gathered}
\Delta J_{g}=J X_{g} \bullet \Delta J \\
P_{i, t}=P_{i, S, t}+P_{i, J, t}+P_{i, z, t}, \quad i=1,2, \cdots, N \\
P_{i, \min } I_{i, t} \leq P_{i, t} \leq P_{i, \max } I_{i, t} \\
\boldsymbol{k}(\boldsymbol{P}, \boldsymbol{I})=0 \\
\boldsymbol{y}(\boldsymbol{P}, \boldsymbol{I}) \leq 0 \\
\sum_{i=1}^{n}\left|A_{l i} P_{i, i n}\right| \leq F_{l, \text { max }}, \quad l=1,2, \cdots b \\
\Delta J_{g} \geq 0, P_{i, S, t} \geq 0, P_{i, J, t} \geq 0, P_{i, z, t} \geq 0, \boldsymbol{I} \in(0,1)
\end{gathered}
$$

In the above equations, $H$ is number of thermal plant; $N$ is number of thermal unit; $T$ is number of time interval; $\boldsymbol{P}$ is thermal unit output column under predicted wind power, its element $P_{i, t}$ is the output of unit i at time t(MW); I is the operation state column of thermal units, its element $I_{i, t}$ is the operation state of thermal $i$ at time $t, P_{w j, t}$ is the predicted power of wind farm $j$ at time $t(\mathrm{MW}) ; L_{t}$ is load forecast at time $t(\mathrm{MW}) ; \Delta S_{g}$ is bilateral transaction reductions of plant $\mathrm{g}(\mathrm{MWh}) ; S X_{g}$ is bilateral transaction cutting factor of plant $\mathrm{g}$; $P_{i, z, t}$ is other component of $P_{i, t}$ for unit $i$ at time t(MW); $N_{g}$ is all the units number of plant g; $\Delta J_{g}$ is the Sangong contract reduction of plant $\mathrm{g}(\mathrm{MWh})$; $J X_{g}$ is Sangong contract cutting factor of plant $g, P_{i, \max }, P_{i, \min }$ is the upper and lower limit of the output of unit $i$ respectively (MW); $n$ is number of node; $b$ is number of branch; $A_{l i}$ is sensitivity factor of branch 1 to net power injection of node $I ; F_{l, \text { max }}$ is the upper limit of power flow for branch $1(\mathrm{MW}) ; F_{i, \text { in }}$ is the net power injection of node $i(\mathrm{MW})$.

Equation (7) is power balance constraint under predicted wind power scenario. Equation (8) is the expression of bilateral transaction reduction of plant $\mathrm{g}$. Equation (9) is the relationship of bilateral transaction reduction between plant $\mathrm{g}$ and the total reductions all the system. Equation (10) is the actual bilateral output limit of plant $g$ at time $t$, which can ensure the bilateral transaction reduction non-negative for plant $g$ at time $t$, preventing the occurrence of the positive adjustment and negative adjustment offset each other during different periods of time, as is shown in Figure 1, constraint (10) will prevent the occur-

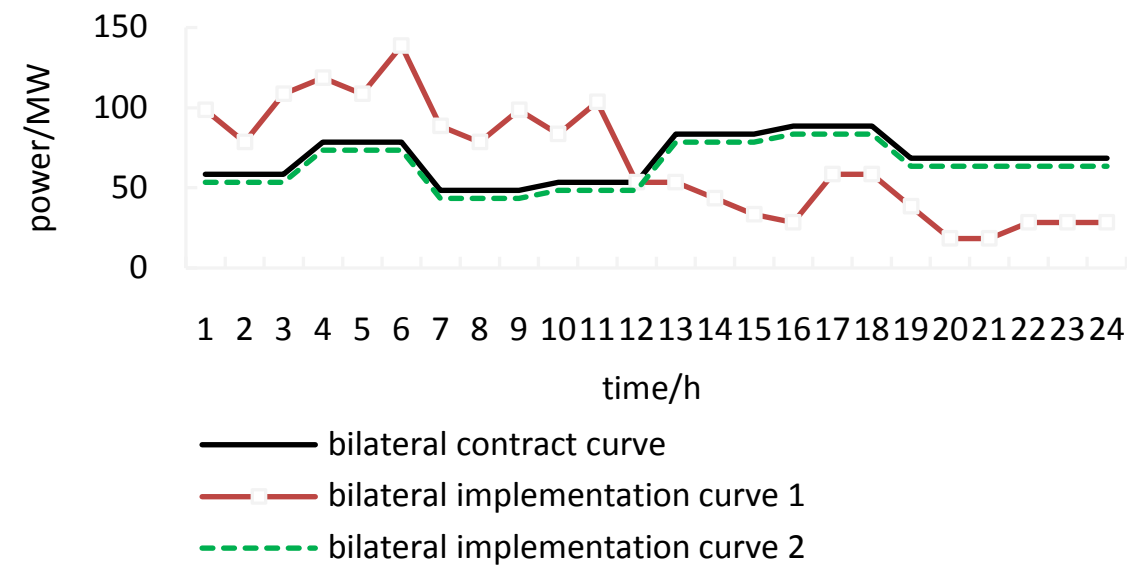

Figure 1. Comparison of two bilateral output curves. 
rence of bilateral output curve 2, and control the output implementation like curve 1. Equation (11) is the expression of Sangong contract reduction of plant g. Equation (12) is the relationship of Sangong contract reduction between plant $\mathrm{g}$ and the total reductions all the system. Equation (13) is the expression based on various power components of unit output. Equation (14) is unit output limit constraint. Equation (14) is unit output limit constraint. Equality constraints (15) and inequality constraints (16) are common basic constraints, including thermal power unit start variables and outage variables related constraints, minimum on/off time constraints, up-regulation and down-regulation reserve constraints, climbing constraints. Equation (17) is power flow limit constraints. Equation (18) is variable limit constraint, $\Delta J_{g} \geq 0$ is contract reduction nonnegative constraints of Sangong contract for plant g, which can prevent Sangong contract reduction is negative, and the bilateral transaction reduction is positive, resulting in Sangong reduction and bilateral reduction offset each other for power plant total contract reduction.

\subsection{Constraints under Wind Power Extreme Scenarios}

Constraints under wind power extreme scenarios is for considering the uncertainty of wind power, to improve the system ability to absorb random wind power, and does not involve the implementation of the transaction, this part constraints include the power balance constraint, the reserve constraint, the power flow constraint, the thermal power unit running limit constraint and the system up and down regulation constraints under the coupling wind power limit scenes.

$$
\begin{gathered}
\sum_{i=1}^{N} P_{i, t}^{s}+\sum_{j=1}^{W} P_{w j, t}^{s}=L_{t} \\
P_{i, \min } I_{i, t} \leq P_{i, t}^{s} \leq P_{i, \max } I_{i, t} \\
\boldsymbol{k}\left(\boldsymbol{P}^{s}, \boldsymbol{I}\right)=0 \\
y\left(\boldsymbol{P}^{s}, \boldsymbol{I}\right) \leq 0 \\
\sum_{i=1}^{n}\left|A_{i i} P_{i, i n}^{s}\right| \leq F_{l, \max }, \quad l=1,2, \cdots b \\
d L_{t}^{s}=L_{t}-\sum_{k=1}^{W} P_{w k, t}^{s} \\
\sum_{i=1}^{N}\left[\min \left\{P_{i, \max }-P_{i, t-1}^{1}, R_{i}\right\} I_{i, t-1} I_{i, t}+P_{\mathrm{i}, \min } u_{i, t}-P_{i, \min } v_{i, t}\right] \geq d L_{t}^{2}-d L_{t-1}^{1} \\
\sum_{i=1}^{N}\left[\min \left\{P_{i, t-1}^{2}-P_{i, \text { min }}, D_{i}\right\} I_{i, t-1} I_{i, t}+P_{i, \min } v_{i, t}-P_{i, \min } u_{i, t}\right] \geq d L_{t-1}^{2}-d L_{t}^{1} \\
I \in(0,1), P_{i, t}^{s} \geq 0
\end{gathered}
$$

In the above equations, $N$ is number of units; the superscript $s$ represents the wind power extreme scenario, 1 is the upper limit of the confidence interval of the wind power, and 2 is the lower limit of the confidence interval, variable with the superscript $s$ indicate that the variable is the value under the wind power extreme scenario $s . \quad u_{i, t}, \quad v_{i, t}$ is start-up variable and switch-off variable of unit $i$ 
at time $t$ respectively; $P_{w j, t}^{s}$ is the output of wind farm $j$ at time $t$ under extreme scenario $\mathrm{s}(\mathrm{MW}) ; P_{i, t-1}^{1}, \quad P_{i, t}^{1}$ is the output of thermal unit $i$ at time $t-1$ and time $t$ under upper extreme scenario 1 respectively(MW); $P_{i, t-1}^{2}, P_{i, t}^{2}$ is the output of thermal unit $\mathrm{i}$ at time $t-1$ and time $\mathrm{t}$ under lower extreme Scenario 2 respectively(MW); $d L_{t}^{s}$ is the equivalent load at time $t$ under extreme scenario $s ; d L_{t-1}^{1}, d L_{t}^{1}$ is the equivalent load at time $t-1$ and $t$ respectively under extreme scenario $1 ; d L_{t-1}^{2}, d L_{t}^{2}$ is the equivalent load at time $t-1$ and $t$ respectively under extreme Scenario $2 ; R_{i}, D_{i}$ is the climbing rate and descent rate of unit $i$ respectively.

Equation (19) is power balance constraint under wind power extreme scenario $s$. Equation (20) is unit output limit constraint. Equality constraints (21) and inequality constraints (22) are common basic constraints, including thermal power unit start variables and outage variables related constraints, minimum on/off time constraints, up-regulation and down-regulation reserve constraints, climbing constraints. Equation (23) is power flow limit constraints. Equation (24) is the expression of equivalent load; Equation (25) is the system up-regulation capacity constraint, the left side indicates the system up regulation capacity from period $t-1$ to $t$, and the right side indicates that the system up-regulation capability needs to be higher than the equivalent load change when wind power across between the extreme scenes. Equation (26) is the system down regulation capacity constraint, the left side indicates the system down regulation capacity from period $t-1$ to $t$, and the right side indicates that the system down regulation capability needs to be higher than the equivalent load change when wind power across between the extreme scenes.

\section{Example}

According to the example, this paper studied the influence of the execution priorities of bilateral electric power contract and Sangong contract to the implementation of the contracts, studied the influence of the power flow restriction and wind power accommodation on the contract implementation, and verified the effectiveness of ensuring the fairness of contract implementation among power plants, verified the validity of the model.

\subsection{Test System Description}

The system is shown in Figure 2: thermal power installed capacity is $1200 \mathrm{MW}$, wind power installed capacity is $150 \mathrm{MW}$, wind power accounts for $11 \%$, the bilateral transaction size is $80 \%$ of electricity demand. Thermal unit parameters are shown in Appendix Table A, the bilateral electric power contract information of power plant is shown in Appendix Table B, wind power and system load forecast data is shown in Appendix Table C.

\subsection{Running Results}

Bilateral transaction cutting factors and Sangong contract cutting factors are calculated according to Appendix Table B as are shown in Table 1. 


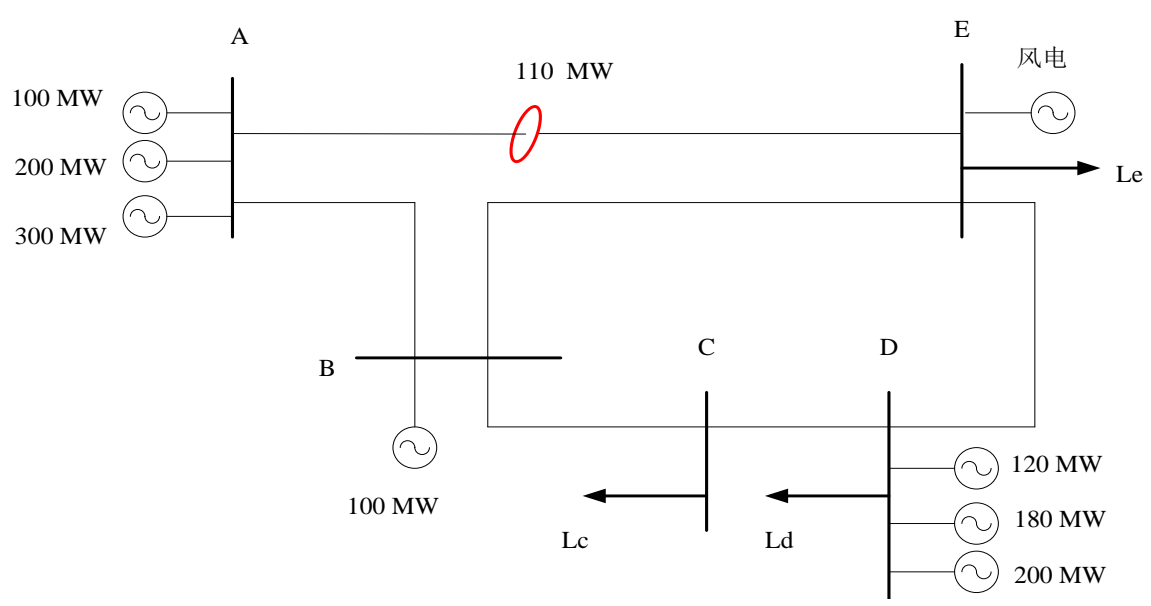

Figure 2. The test system.

Table 1. Cutting factors for power plants.

\begin{tabular}{ccccc}
\hline Power plant & Bilateral/MW*h & Sangong/MW*h & $\begin{array}{c}\text { Bilateral } \\
\text { cutting factors }\end{array}$ & $\begin{array}{c}\text { Sangong } \\
\text { cutting factors }\end{array}$ \\
\hline A & 6447 & 1611.75 & 0.5 & 0.5 \\
B & 1074.5 & 268.63 & 0.083 & 0.083 \\
D & 5372.5 & 1343.13 & 0.417 & 0.417 \\
\hline
\end{tabular}

- The Impact of Execution Priority on Contract implementation.

According to the different execution priorities, the following two cases are studied to compare the impact of the execution priority on the results of the operation:

1) Case 1: Bilateral transactions are given priority, $W_{1}$ takes $4, W_{2}$ takes 1 , confidence interval takes $98 \%$;

2) Case 2: Sangong contracts are given priority, $W_{1}$ takes $1, W_{2}$ takes 4 , confidence interval takes $98 \%$;

Contract reductions and power generation costs of two cases are shown in Table 2, bilateral transaction implementation of Case1 is shown in Figure 3(a), bilateral transaction implementation of Case2 is shown in Figure 3(b).

- Unit Commitment, Generation Cost and Wind Power Accommodation Ability.

Under the premise of giving priority to the implementation of bilateral transactions, the influence of confidence interval on unit commitment, wind power consumption and power generation cost is studied, using 200 random wind power scenes generated by MATLAB, the wind power accommodation ability of unit commitment is tested, results are shown in Table 3.

\subsection{Analysis of Running Results}

(1) Validity of the Priority Coordination of Different Power Components and Execution Fairness of Power Plants.

As can be seen from Table 2, the bilateral transaction reduction of Case 1 is reduced by $83.66 \%$ compared to that of Case 2 , Sangong contract reduction of 


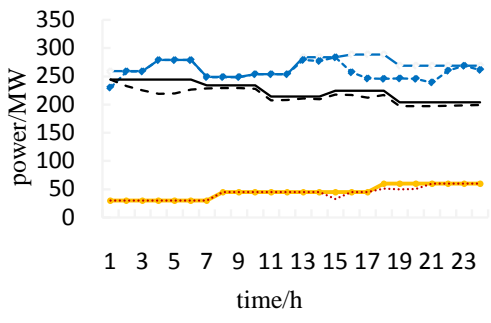

(a)

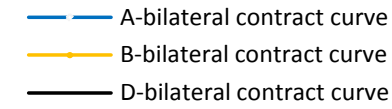

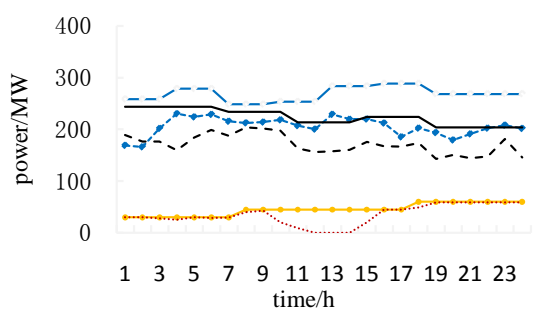

(b)

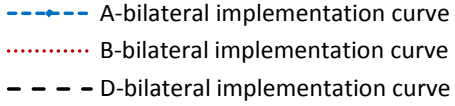

Figure 3. (a) Bilateral implementation when bilateral transactions execution is given priority; (b) Bilateral implementation when Sangong contracts execution is given priority.

Table 2. Contract reductions and generation costs under different execution priority.

\begin{tabular}{|c|c|c|c|c|c|c|c|c|c|}
\hline \multirow{2}{*}{ Cases } & \multicolumn{4}{|c|}{ Bilateral reductions/MWh } & \multicolumn{4}{|c|}{ Sangong reductions/MWh } & \multirow{2}{*}{$\begin{array}{c}\text { Generation } \\
\text { costs/ } ¥\end{array}$} \\
\hline & A & B & $\mathrm{D}$ & Total & A & B & $\mathrm{D}$ & Total & \\
\hline Case 1 & 248.57 & 41.26 & 207.31 & 497.14 & 1283.01 & 212.98 & 1070.03 & 2566.02 & 2128408.1 \\
\hline Case 2 & 1521.36 & 252.55 & 1268.8 & 3042.71 & 0 & 0 & 0 & 0 & 2113071.1 \\
\hline
\end{tabular}

Table 3. Results under different wind power confidence intervals.

\begin{tabular}{ccccc}
\hline Units & \multicolumn{4}{c}{ Confidence intervals } \\
\cline { 2 - 5 } & all day & all day & all day & all day \\
G1 & $1-5$ & $1-5$ & 1 - 5 & $1-5$ \\
G3 & all day & all day & all day & all day \\
G4 & all day & all day & all day & all day \\
G5 & all day & all day & all day & all day \\
G6 & $1-2,14-21$ & $1-2,13-21$ & $1-2,12-22$ & $1-3,10-22$ \\
G7 & all day & all day & all day & all day \\
Generation costs/¥ & $2,105,317.9$ & $2,108,770.6$ & $2,115,675.9$ & $2,128,408.1$ \\
Wind power consumption rate/\% & 64 & 79 & 93 & 99.5 \\
\hline
\end{tabular}

Case 2 is reduced by $100 \%$ compared to that of Case 1 . Case 1 is given the priority for bilateral transactions, Case 2 is given the priority for Sangong contract, and the results show that the model can flexibly achieve the coordination of different power components. In addition, the bilateral transaction is given priority, the system's generation cost and the system total contract reductions are higher, this is because the electric power contract not only requires to finish the power quantities determined by the contract, but also requires the output curve in accordance with the contract power curve as much as possible, the implementation of electric power contracts will cure more regulatory resources, making the implementation more difficult. 
Figure 3 shows the bilateral power implementation curves in both cases. It can be seen that the bilateral implementation curves under Case 1 are better, with the deviation of the bilateral power contract curve is smaller, however, the deviation of bilateral execution curve with the contract curve under Case 2 is larger, contract execution is poor. Table 2 and Figure 3 both verify the effectiveness of the model in coordinating the execution priorities of different charge components.

According bilateral transaction reductions and Sangong reductions in Table 2, it can be seen that the power plant bilateral reduction is proportional to total bilateral reduction, the proportion is equal to bilateral cutting factor of this plant, such conclusion can be get about Sangong contract reduction, which shows that the model can ensure the fairness implementation among power plants.

(2) The Impact of Confidence Intervals on Wind Power Consumption Ability and Power Generation Costs.

According to Table 3, the unit operation hours, generation costs and wind power consumption rate all increase as the confidence interval increases. This is because the more possible wind power output is considered when the confidence interval is larger, the unit operation hours increase to ensure that the system has stronger ability to adjust and resulting the increase of generation costs. In this study, when the confidence interval reaches $98 \%$, the wind power consumption rate reaches $99.5 \%$, unit commitment reliability reaches more than $99 \%$.

(3) The Impact of the Flow Constraint on Contract Implementation.

The power transfer factors of line A-E on the node B, C, D, E are -0.112 , $-0.2629,-0.321$ and -0.4805 . Considering the volatility of wind power and the priority execution of bilateral transactions, the confidence interval is $98 \%$, and the contract reductions ignoring the power flow constraints are obtained as shown in Table 4. The bilateral transaction execution curves are shown in Figure 4, and there is a comparison of contract reductions between the two cases of considering power flow limit and ignoring power flow limit in Figure 5.

Compare Table 4 with Case1 in Table 2, it can be seen that there is significant decrease in the amount of contract reductions and power generation cost when there is no power flow limits. Compare Figure 4 with Figure 3(a), the bilateral

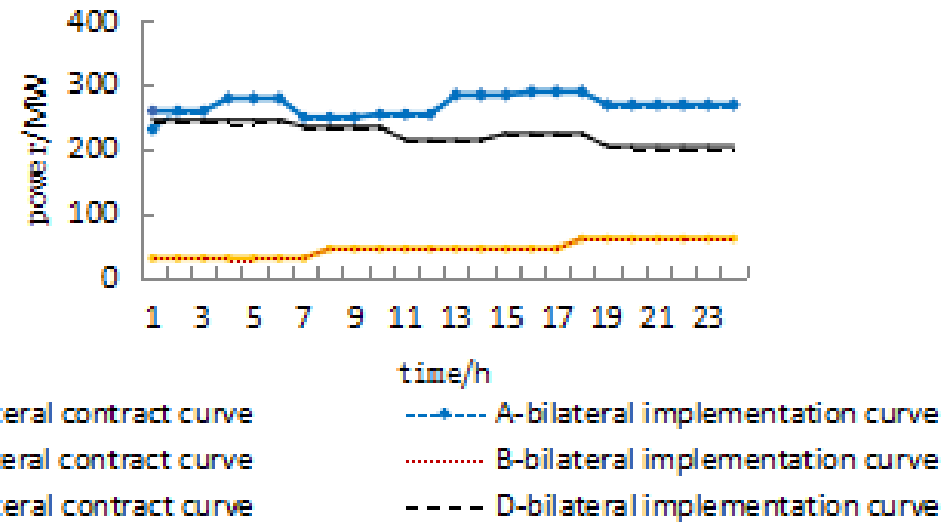

Figure 4. Bilateral implementation curves under conditions ignoring flow limits. 


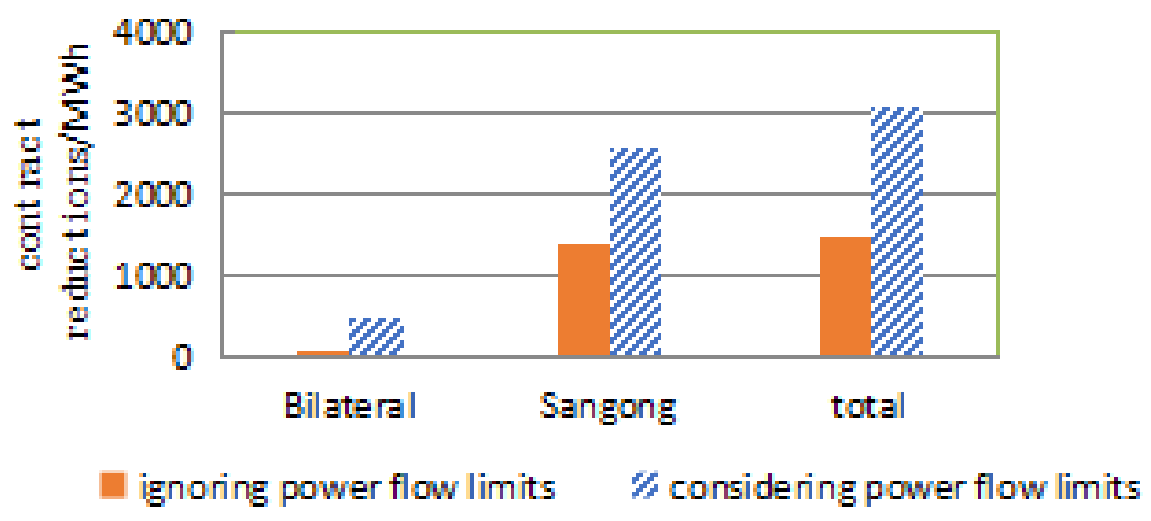

Figure 5. The impact of power flow limits on contract reductions.

Table 4. Contract implementation in the case of ignoring power flow constraints.

\begin{tabular}{|c|c|c|c|c|}
\hline \multirow{2}{*}{ Case } & \multicolumn{3}{|c|}{ Contract reductions/MWh } & \multirow{2}{*}{ Generation cost/ } \\
\hline & Total & Bilateral & Sangong & \\
\hline \multirow{3}{*}{$\begin{array}{l}\text { Ignoring power flow } \\
\text { limits }\end{array}$} & & A: 28.63 & A: 706.99 & \\
\hline & 1471.23 & B: 4.75 & B: 117.36 & 1969647.8 \\
\hline & & D: 23.87 & D: 589.63 & \\
\hline
\end{tabular}

transaction execution curve is much closer to the contract curve when there is no power flow limits. Compare contract reductions in Figure 5, it is clear that the line blockage will not be conducive to the implementation of the contract.

(4) The Impact of Wind Farm Location on Contract Implementation.

Wind power location affects power trend, which will have different effects on the implementation of the contract. Three cases has been studied. Case0: no wind; Case-E: Wind farm at point E; Case-A: Wind farm at point A. Contract implementations of Case0, Case-E and Case-A are shown in Table 5. Comparison of contract reductions in three cases is shown in Figure 6.

According to Table 5, it can be seen that in three cases of Case0, Case-E and Case-A: wind farm at $\mathrm{E}$ point is conducive to the implementation of the contract, the contract reduction is minimal; wind farm at point $\mathrm{A}$ is not conducive to the implementation of the contract, the contract reduction is largest. Because wind power causes reverse trend in the blocking line in Case-E, which can promote the implementation of contract power, bilateral contract reduction decreases by $57.71 \%$ and Sangong contract reduction decreases by $20.21 \%$ compared to Case0; the other hand, wind power causes positive current In the blocking line in Case-A, squeezes the thermal power transmission channel, affecting the implementation of the contract, bilateral contract reduction increases by $221.33 \%$ and Sangong contract reduction increases slightly. It is pointed out that the influence of wind power consumption on contract execution should be determined together with the trend. If the conclusion can be used rationally, it can promote the consumption of wind power and the implementation of bilateral transaction at the same time through reasonable planning and market design. 


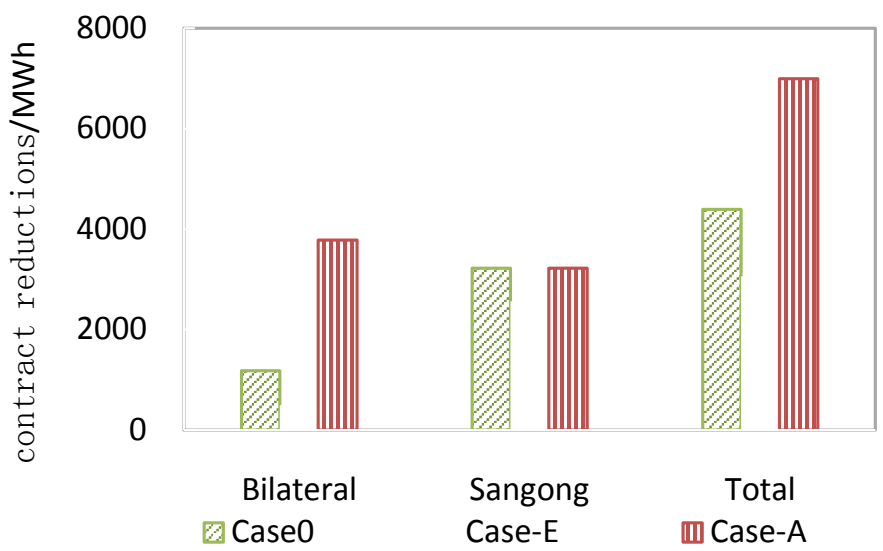

Figure 6. Comparison of contract reductions under different cases.

Table 5. The impact of wind farm location on contract implementation.

\begin{tabular}{cccc}
\hline \multirow{2}{*}{ Cases } & \multicolumn{3}{c}{ Contract reductions/MWh } \\
\cline { 2 - 4 } & Total & Bilateral & Sangong \\
\hline \multirow{2}{*}{ Case0 } & A: 587.74 & A: 1607.98 \\
& & B: 97.57 & B: 266.93 \\
& & D: 490.18 & D: 1341.06 \\
Case-A & A: 1888.60 & A: 1610.47 \\
& & B: 313.51 & B: 267.34 \\
& & D: 1575.10 & D: 1343.13 \\
Case-E & & A: 248.57 & A: 1283.01 \\
& 3063.16 & B: 41.26 & B: 212.98 \\
& & D: 207.31 & D: 1070.03
\end{tabular}

\section{Conclusion}

This paper validates the effectiveness of the proposed unit commitment model, which can effectively ensure new energy consumption, transaction execution and the fairness among power plants, power grid security and power generation economy, this paper analyzed the influence of different power components execution priorities on the results of transaction execution, and analyzed the influence of different confidence interval selection on unit combination reliability and wind power consumption ability, and analyzed the influence of wind power location on transaction execution, and proposed that when the wind power causes reverse trend in the block line, it will promote the implementation of the contract, and when wind power causes positive trends, it will hinder the implementation of the contract, the conclusion can provide reference for wind power planning and bilateral trading market.

\section{Acknowledgements}

This work was financially supported by State Grid Corporation Science and Technology Project (DZ71-15-086) fund. 


\section{References}

[1] Han, Z.H. (2008) Cleaning Model and Bidding Manners of Bilateral Bargaining in Wholesale Competition Power Market. Electrotechnical Application, 27, 27-31(in Chinese).

[2] Han, J.R., Zeng, M., Duan, J.H. and Li Na. (2013) The Bilateral Electricity Market Modes of Typical Countries. East China Electric Power, 1, 17-23(in Chinese).

[3] Zeng, M., Liu, C., Duan, J.H. and Li Na. (2013) The Bilateral Electricity Market Modes of Typical Countries and Our Reference From America and Nordic. East china Electric Power, 41, 5-10(in Chinese).

[4] Zeng, M., Duan, J.H., Li, N. and Dong, J. (2013) The Experience of British Bilateral Electricity Market Modes. East china Electric Power, 41, 1-4(in Chinese).

[5] Zeng, M. Cheng, J., Duan, J.H., Dong, J. and Liu, C.(2013) The Bilateral Electricity Market Modes of Typical Countries and our Reference from Australia And Russia. East China Electric Power, 1, 11-16(in Chinese).

[6] Kebriaei, H. and Majd, V.J. (2009) A Simultaneous Multi-Attribute Soft-Bargaining Design for Bilateral Contracts. Expert Systems with Applications, 36, 4417-4422. https://doi.org/10.1016/j.eswa.2008.05.003

[7] Zhang, X., Wang, X.F., Chen, H.Y., Wang, J.X. (2003) Survey of Bilateral Transactions in Power Market. Electric Power Automation Equipment, 11, 77-86(in Chinese).

[8] Zhang, X., Wang, X.F., Wang, J.X. and Hu, Z.H. (2004) Application of Block Trading in Bilateral Market. Automation of Electric Power Systems, 11, 13-16(in Chinese).

[9] Zou, X.Y. (2007) The Bargain Game And Power Energy Allocation of Bilateral Transaction in Power Market. Demand Side Management, 4, 34-36(in Chinese).

[10] Wen, T., Du, S.H. and Su, J. (2013) Available Transfer Capability Determination Considering Bilateral Exchange. Transactions of the Chinese Society of Agricultural Engineering, 29, 161-166(in Chinese).

[11] Zhang, W. and Fan, Y.H. (2008) Analysis on Bilateral Transaction Simulation of Central China Electricity Market. Automation of Electric Power System, 32, 97-102(in Chinese).

[12] Zhang, S.L., Zhang, Y., Chen, H.Y. and Qu, S.Q. (2009) Successful Bilateral Transactions in South China Electricity Market. Electric Power Automation Equipment, 29, 94-99(in Chinese).

[13] Liu, F., Pan, Y., Yang, J.F., Zhou, J.Y., Zhou, J.Y., etc. (2015) Unit Commitment Model for Combined Optimization of Wind Power-Thermal Power-Pumped Storage Hydro. Proceedings of the CSEE, 4, 766-775(in Chinese).

[14] Liu, F., Pan, Y., Liu, H., Ding, Q. and Wang, Z.M. (2013) Research on Piecewise Exponential Distribution Model of Wind Power Forecasting Error. Automation of Electric Power Systems, 18, 14-19(in Chinese). 


\section{Appendix}

Table A. Parameters of thermal units.

\begin{tabular}{|c|c|c|c|c|c|c|c|c|c|c|c|}
\hline \multirow{2}{*}{ Plants } & \multirow{2}{*}{ Units } & \multirow{2}{*}{$\begin{array}{c}\text { Upper } \\
\text { Output/MW }\end{array}$} & \multirow{2}{*}{$\begin{array}{c}\text { Lower } \\
\text { Output/MW }\end{array}$} & \multirow{2}{*}{$\begin{array}{c}\text { Ramping } \\
\text { Capacity/(MW/h) }\end{array}$} & \multirow{2}{*}{$\begin{array}{l}\text { Lower } \\
\text { Startup } \\
\text { Time/h }\end{array}$} & \multirow{2}{*}{$\begin{array}{c}\text { Lower } \\
\text { Stop } \\
\text { Time/h }\end{array}$} & \multicolumn{3}{|c|}{ Coal Consumption Rate } & \multirow{2}{*}{$\begin{array}{l}\text { Startup } \\
\text { Cost } / ¥\end{array}$} & \multirow{2}{*}{$\begin{array}{c}\text { Coal } \\
\text { Price/(¥/GJ) }\end{array}$} \\
\hline & & & & & & & $\mathrm{a} / \mathrm{GJ}$ & $\mathrm{b} /(\mathrm{GJ} / \mathrm{MWh})$ & $\mathrm{c} /(\mathrm{GJ} / \mathrm{MW} 2 \mathrm{~h})$ & & \\
\hline \multirow{3}{*}{ A } & 1 & 100 & 10 & 50 & 4 & 4 & 176.9 & 13.5 & 0.0004 & 100 & 7.7467 \\
\hline & 2 & 200 & 50 & 60 & 2 & 3 & 129.9 & 32.6 & 0.0004 & 300 & 7.7418 \\
\hline & 3 & 300 & 60 & 30 & 1 & 1 & 137.4 & 17.6 & 0.0004 & 100 & 7.7424 \\
\hline \multirow[t]{2}{*}{ B } & 4 & 100 & 20 & 30 & 2 & 2 & 125.8 & 20 & 0.0003 & 200 & 7.7436 \\
\hline & 5 & 120 & 20 & 40 & 1 & 1 & 140.6 & 30 & 0.0006 & 200 & 7.7421 \\
\hline \multirow[t]{2}{*}{$\mathrm{D}$} & 6 & 180 & 30 & 50 & 2 & 1 & 145.7 & 40 & 0.0006 & 300 & 7.7436 \\
\hline & 7 & 200 & 40 & 40 & 1 & 2 & 156.9 & 10 & 0.0006 & 100 & 7.7410 \\
\hline
\end{tabular}

Table B. Forecast load and forecast wind power.

\begin{tabular}{|c|c|c|c|c|c|c|c|c|c|c|c|}
\hline Hour & $\begin{array}{c}\text { Load } \\
(\mathrm{Lc} / \mathrm{Ld} / \mathrm{Le}) / \mathrm{MW}\end{array}$ & $\begin{array}{l}\text { Forcast wind } \\
\text { power/MW }\end{array}$ & Hour & $\begin{array}{c}\text { Load } \\
(\mathrm{Lc} / \mathrm{Ld} / \mathrm{Le}) / \mathrm{MW}\end{array}$ & $\begin{array}{l}\text { Forcast wind } \\
\text { power/MW }\end{array}$ & Hour & $\begin{array}{c}\text { Load } \\
(\mathrm{Lc} / \mathrm{Ld} / \mathrm{Le}) / \mathrm{MW}\end{array}$ & $\begin{array}{l}\text { Forcast wind } \\
\text { power/MW }\end{array}$ & Hour & $\begin{array}{c}\text { Load } \\
(\mathrm{Lc} / \mathrm{Ld} / \mathrm{Le}) / \mathrm{MW}\end{array}$ & $\begin{array}{l}\text { Forcast wind } \\
V \text { power/MW }\end{array}$ \\
\hline 1 & 206.40 & 44 & 7 & 224.46 & 100 & 13 & 242.06 & 84 & 19 & 218.66 & 10 \\
\hline 2 & 211.78 & 70.2 & 8 & 230.13 & 100 & 14 & 241.20 & 80 & 20 & 212.45 & 5 \\
\hline 3 & 211.56 & 76 & 9 & 227.85 & 78 & 15 & 242.29 & 78 & 21 & 214.44 & 6 \\
\hline 4 & 212.24 & 82 & 10 & 227.07 & 64 & 16 & 229.26 & 32 & 22 & 227.71 & 56 \\
\hline 5 & 213.02 & 84 & 11 & 242.87 & 100 & 17 & 220.00 & 4 & 23 & 227.68 & 82 \\
\hline 6 & 214.83 & 84 & 12 & 242.70 & 92 & 18 & 215.58 & 8 & 24 & 216.25 & 52 \\
\hline
\end{tabular}

Table C. Bilateral electric power contract information of power plant A, B, D.

\begin{tabular}{cccccccccccc}
\hline Time & A/MW & B/MW & D/MW & Time & A/MW & B/MW & D/MW & Time & A/MW & B/MW & D/MW \\
\hline 1 & 258.625 & 29.771 & 243.854 & 9 & 248.625 & 44.771 & 233.854 & 17 & 288.625 & 44.771 & 223.854 \\
2 & 258.625 & 29.771 & 243.854 & 10 & 253.625 & 44.771 & 233.854 & 18 & 288.625 & 59.771 & 223.854 \\
3 & 258.625 & 29.771 & 243.854 & 11 & 253.625 & 44.771 & 213.854 & 19 & 268.625 & 59.771 & 203.854 \\
4 & 278.625 & 29.771 & 243.854 & 12 & 253.625 & 44.771 & 213.854 & 20 & 268.625 & 59.771 & 203.854 \\
5 & 278.625 & 29.771 & 243.854 & 13 & 283.625 & 44.771 & 213.854 & 21 & 268.625 & 59.771 & 203.854 \\
6 & 278.625 & 29.771 & 243.854 & 14 & 283.625 & 44.771 & 213.854 & 22 & 268.625 & 59.771 & 203.854 \\
7 & 248.625 & 29.771 & 233.854 & 15 & 283.625 & 44.771 & 223.854 & 23 & 268.625 & 59.771 & 203.854 \\
8 & 248.625 & 44.771 & 233.854 & 16 & 288.625 & 44.771 & 223.854 & 24 & 268.625 & 59.771 & 203.854 \\
\hline
\end{tabular}


Submit or recommend next manuscript to SCIRP and we will provide best service for you:

Accepting pre-submission inquiries through Email, Facebook, LinkedIn, Twitter, etc. A wide selection of journals (inclusive of 9 subjects, more than 200 journals)

Providing 24-hour high-quality service

User-friendly online submission system

Fair and swift peer-review system

Efficient typesetting and proofreading procedure

Display of the result of downloads and visits, as well as the number of cited articles Maximum dissemination of your research work

Submit your manuscript at: http://papersubmission.scirp.org/

Or contact epe@scirp.org 